\title{
"Tias" e "novinhas": envelhecimento e relações intergeracionais nas experiências de travestis trabalhadoras sexuais em Belo Horizonte
}

\author{
Vanessa Sander \\ Doutoranda do Programa de Pós-Graduação em Ciências Sociais da Unicamp \\ vanessasander@gmail.com \\ Lorena Hellen de Oliveira \\ Mestranda do Programa de Pós-Graduação em Antropologia da UFMG
}

\begin{abstract}
Resumo O presente artigo pretende costurar reflexões sobre as relações intergeracionais entre travestis trabalhadoras sexuais e suas noções e perspectivas de envelhecimento e periodização da vida, por meio de dados extraídos de nossas pesquisas etnográficas que partiram de diferentes áreas de prostituição de Belo Horizonte. Concebendo as categorias referentes às gerações e o envelhecimento como produções discursivas, buscou-se compreender quais narrativas são acionadas pelas travestis para dar contornos e singularidades às suas experiências. O foco reside nas relações intergeracionais entre "tias" e "novinhas", como são chamadas as travestis veteranas e novatas: seus conflitos, afetos, dinâmicas distintivas e memórias de experiências compartilhadas. A constituição dessas categorias nativas aponta para um emaranhado de relações, vínculos e conflitos, que constituem redes de suporte social atravessadas pelo mercado do sexo.
\end{abstract}

Palavras-chave: travestis; envelhecimento; gerações; prostituição; etnografia.

\section{Introdução: "travestilizando" temporalidades}

$\mathrm{O}$ presente artigo pretende costurar reflexões sobre as relações intergeracionais entre travestis trabalhadoras sexuais e suas noções e perspectivas de envelhecimento e periodização da vida, por meio de dados extraídos de nossas pesquisas etnográficas, ${ }^{1}$ que partiram de diferentes áreas de prostituição ${ }^{2}$ de Belo Horizonte. Concebendo as categorias geracionais e o envelhecimento como produções discursivas,

1. Nossas incursões etnográficas e pesquisas individuais tiveram uma origem comum: o projeto de pesquisa Direitos e Violência na Experiência de Travestis e Transexuais da Cidade de Belo Horizonte: construção de um perfil social em diálogo com a população, realizado pelo Núcleo de Direitos Humanos Cidadania LGBT (NUH/UFMG) e coordenado pelo Prof. Dr. Marco Aurélio Máximo Prado.

2. É importante pontuar que nossas investigações foram levadas a considerar os espaços de prostituição dessas pessoas, não por acreditar que elas sejam originárias do mercado do sexo, mas atentando para esse universo como o principal destino - muitas vezes o único para a sociabilidade das travestis no Brasil, dadas as dinâmicas de marginalização e exclusão a que elas estão sujeitas, principalmente nas instituições educacionais e no mercado de trabalho formal. 
buscou-se compreender quais narrativas são acionadas pelas travestis para dar contornos e singularidades às suas experiências. $\mathrm{O}$ foco reside nas relações intergeracionais entre "tias" e "novinhas", como são chamadas as travestis veteranas e novatas: seus conflitos, afetos, dinâmicas distintivas e memórias de experiências compartilhadas. A constituição dessas categorias nativas referentes à geração aponta para um emaranhado de relações, vínculos e tensões, que constituem redes de suporte social atravessadas pelo mercado do sexo. ${ }^{3}$

Alguns autores vêm discutindo, há algum tempo, o caráter contingente, histórico e cultural da velhice em nossas sociedades (Debert, 1999, 2000; Britto da Motta, 1999; Peixoto, 2000; Simões, 2004; Barros, 2006) e analisam o fenômeno a partir da sua articulação com outros marcadores sociais da diferença, como gênero, raça, sexualidade e classe, revelando a heterogeneidade existente nas possibilidades de viver e perceber a passagem do tempo. Nesse sentido, a compreensão do processo de envelhecimento a partir de sua constituição social amplia o escopo de seus significados, não mais restritos a uma ideia de cronologia. Nesta perspectiva, Simões (2004, p. 423) apresenta o "paradigma do curso da vida", uma alternativa de reflexão às abordagens que até então priorizaram a perspectiva de fases sucessivas e progressivas de experiência de vida. Conforme pontua:

O paradigma do curso da vida se coloca como tendência alternativa voltada para o reconhecimento de que qualquer ponto da trajetória de vida precisa ser analisado de uma perspectiva dinâmica, como consequência de experiências passadas e expectativas futuras, e de uma integração entre os motivos pessoais e os limites do contexto social e cultural correspondente.

Esta é uma perspectiva muito válida nas análises sobre envelhecimento nas experiências das travestis trabalhadoras sexuais, uma vez que o pertencimento a determinada geração se dá, sobretudo, pela evocação e construção de um passado compartilhado e pela própria ideia do que é tornar-se velha (ou idosa) em um contexto social marcado por inúmeras singularidades que dificultam alcançar tal período. Assim como o signo "mulher", o signo "travesti" tem sua própria especificidade constituída dentro e mediante configurações historicamente específicas de relações de gênero. Seu fluxo semiótico assume significados particulares em discursos de diferentes "feminilidades", nos quais vem a simbolizar trajetórias, circuns- tâncias materiais e experiências culturais históricas particulares (Brah, 2006, p. 341).

Atualmente, é possível localizar um conjunto de estudos discutindo o envelhecimento de travestis e transexuais - os significados atribuídos a esse processo -, além das estratégias de resistência para vivenciar o período (Siqueira, 2004; Antunes; Mercadante, 2010; Costa, 2013; Nogueira, 2013). Tais investigações apontam a existência de uma série de elementos que organizam e definem corporalidades e performatividades específicas nestes cenários, os quais irão situar os sujeitos, com o passar do tempo, nas categorias de "tias", "mães", "mariconas" e "bichas velhas", conforme as dinâmicas distintivas em suas redes de sociabilidade e as ocupações que podem desempenhar.

Embora não citado no conjunto de obras que analisam especificamente os processos de envelhecimento, o trabalho de Tiago Duque (2009) traz importantes insights a respeito das dinâmicas de diferenciação intergeracional, que se inscrevem a partir do corpo. O autor discute como os processos de composição de um "feminino travesti", construídos por uma geração de adolescentes travestis, podem estar em constantes tensões com os modelos de gerações precedentes. Pensar sobre geracionalidade no caso das travestis, portanto, requer considerar as singularidades envolvidas nesse contexto e o tensionamento simbólico que elas produzem. Segundo Nogueira (2013, p. 22),

no interior da travestilidade, os marcadores geracionais e etários são desmontados, ainda que parcialmente, e são questionados por categorias e elementos de ordem política, histórica, social, cultural e corporal, elementos estes instituídos a partir de relações sociais, confrontando muitas vezes as moralidades médicas, jurídicas, religiosas e educacionais.

É interessante pensar que, ao nos atermos aos processos de envelhecimento das travestis, é possível contestar tanto as noções de gênero quanto as de velhice como essenciais, universais e fixas. Conforme assinalaram Antunes e Mercadante (2011), ambos os conceitos se concretizam apenas enquanto performatividades que, para ser reconhecidas e legitimadas, procuram operar por meio de certas convenções sociais. Indo mais adiante, é possível, até mesmo, questionar a própria noção tradicional de temporalidade nestes cenários, uma vez que os contextos precários ${ }^{4}$ vivenciados pelas travestis acabam por distorcer a marcação dos estágios de infância, juventude e velhice em suas vidas. Percebe-se, portanto, que a relação estabelecida com o próprio tempo pode se dar de uma

3. Agradecemos pelos cuidadosos comentários de Carlos Eduardo Henning e Gustavo Saggese nas primeiras versões deste texto, apresentadas na XXX Reunião Brasileira de Antropologia e no II Seminário Internacional Desfazendo Gênero.

4. A noção de precariedade aqui empregada remete a um enquadramento seletivo e diferenciado da violência (Butler, 2015). 
maneira singular, estando diretamente relacionada a um contexto mais amplo de violências, negação de direitos e exclusão social desta população, o qual, ao mesmo tempo que produz tais experiências, também as limita.

Além disso, o diálogo com um conjunto mais amplo de pesquisas que articulam gênero, (homo) sexualidade e velhice lança luz sobre problemáticas congêneres levantadas durante a investigação sobre travestis. Em se tratando da intersecção entre envelhecimento e sujeitos que vivenciam práticas sexuais homoeróticas, além da produção de Julio Simões (2004), destacam-se os trabalhos de Lacombe (2013), Henning (2014), Saggese (2015), Passamani (2015) e Seffnner e Duarte (2015).

Esses estudos, de uma forma geral, descrevem os modos de subjetivação dos sujeitos diante das experiências da velhice, suas formas de sociabilidade e as dinâmicas de diferenciação implicadas nesse processo; também analisam os agenciamentos e estratégias de resistência empreendidas por eles diante dos discursos normativos invocados na produção do que seria um envelhecimento "socialmente legítimo". Dessa forma, é possível refletir sobre a plasticidade e conjunturalidade do curso da vida à luz de expectativas heteronormativas (Henning, 2016), assim como analisar as marcas distintivas inscritas nos processos de envelhecimento em determinadas trajetórias de vida, redes de sociabilidade e contextos específicos.

Através das tensões e vínculos vividos por nossas interlocutoras - travestis que se identificam como pertencentes a distintas gerações -, percebe-se como diferença e comunalidade são signos relacionais, entretecendo narrativas de diferença ou semelhança com aquelas de um passado e destinos coletivos compartilhados. Paradoxalmente, a comunalidade que é evocada pode tornar-se significativa com um discurso de diferença (Brah, 2006, p. 372). Assim, a experiência emerge como um lugar de contestação: um espaço discursivo em que posições de sujeito e subjetividades diferentes e diferenciais são inscritas, reiteradas ou repudiadas.

A noção de experiência aqui empregada alinha-se à perspectiva de Scott (1999), segundo a qual os processos históricos são constitutivos dessa experiência, posicionando os sujeitos e produzindo (eles mesmos) suas experiências. Segundo essa autora, "não são os indivíduos que têm experiência, mas os sujeitos é que são constituídos através da experiência” (p. 5). Nesse sentido, conforme a literatura e nossas próprias etnografias apontam, as narrativas das travestis sobre o envelhecimento passam pela construção de distintas corporalidades e pelo compartilhamento e produção de memórias que as situam em determinada geração.

Por isso, procuramos neste texto analisar algumas falas, depoimentos e diálogos recolhidos em campo, os quais evidenciam as perspectivas atribuídas aos processos de envelhecimento e as estratégias e relações que esses processos engendram, dando atenção às relações intergeracionais e considerando como elas são marcantes no cotidiano do trabalho sexual e do convívio doméstico. A seleção das interlocutoras não foi realizada sobre a base específica de uma faixa etária, pois, como será explorado mais adiante, as noções de envelhecimento ou de geração vivenciadas pelas travestis estão calcadas menos na idade que nas dinâmicas do mercado do sexo, que valorizam fortemente a juventude.

Segundo Debert (2000), quando a referência do pesquisador no tratamento de categorias como velhos, jovens, adolescentes e crianças é o número de anos vividos a partir da data de nascimento ou a aparência de cada um, perde-se a plasticidade das formas pelas quais o curso da vida é concebido em sociedades distintas, bem como o sentimento investido em grupos etários e a importância desses grupos e categorias na organização social. Portanto, procuramos justapor reflexões proporcionadas pela pesquisa etnográfica, bem como pelos estudos anteriormente citados sobre envelhecimento LGBT, explorando as noções de periodização da vida, temporalidade e futuridade no cenário investigado.

\section{"Tias" e "novinhas": relações intergeracionais}

De acordo com Guita Grin Debert (1999), o modo pelo qual a vida é periodizada e o tipo de sensibilidade investida na relação entre diferentes faixas etárias é, na antropologia, uma dimensão central para a compreensão das formas de sociabilidade em diferentes contextos e em sociedades distintas. A análise das categorias e dos grupos de idade mostrou-se parte importante de nossas pesquisas, pois as transformações corporais características do tornar-se travesti, seus estilos e técnicas, o cotidiano do trabalho sexual e da vida doméstica estão perpassados por categorias nativas referentes às gerações e aos vínculos e conflitos que experienciam.

Logo de início, ficou muito evidente como o mercado do sexo impõe uma certa temporalidade que pode ser bastante excludente em relação aos processos de envelhecimento. Os trinta anos nos foram repetidamente narrados como uma marca etária associada à perda da juventude, do frescor e dos clientes. A juventude aparece, frequentemente, como um valor determinante para o sucesso e os maiores lucros na prostituição. Percebemos que a dinâmica da "pista" (como são chamadas as áreas de prostituição) opera- 
va em um movimento de elisão periódica dos corpos mais velhos, que iam se tornando obsoletos; estes eram deslocados da luz à sombra, das áreas mais movimentadas às mais ermas e desabitadas, caminhando até sua exclusão ou deslocamento para outras atividades ligadas ao mercado do sexo. ${ }^{5}$

No entanto, a ideia de que o envelhecimento e a progressiva indesejabilidade é algo inescapável e generalizável não se comprova de todo nas narrativas das "tias". Muitas travestis mais velhas relatam que, embora tenham percebido uma considerável diminuição no número de interessados em seus serviços, o passar do tempo terminou por estreitar laços com certos clientes antigos, que elas atendem há muitos anos e com os quais construíram uma relação em que afirmam poder aproveitar seus anos de experiência e conhecimento das preferências específicas do parceiro.

A interrupção de grande parte do trabalho sexual, atribuída à falta de interesse dos clientes, leva à busca de novas estratégias e caminhos profissionais para aquelas não mais tão desejadas na "pista". Desta forma, na medida em que são periodicamente excluídas do mercado sexual por causa da idade considerada avançada, as veteranas encontram novos lugares em suas redes; transicionam da saída das ruas e do abandono da prostituição propriamente dita para outras ocupações ainda fortemente conectadas ao trabalho sexual. Muitas delas passam a trabalhar como pensionistas, cafetinas ou "bombadeiras". ${ }^{6}$ Por isso, conseguem manter grande influência nas "pistas", sendo muito importantes na educação, na transformação dos corpos e nos cuidados das mais jovens.

O depoimento a seguir ocorreu após uma situação de tensão entre Maitê, ${ }^{7}$ uma das travestis veteranas e mais experientes da "pista", e Penélope, jovem e considerada uma das mais bonitas da rua. Naquele momento, Penélope havia "bombado" os glúteos recentemente. Além de exibir com orgulho sua "bunda babadeira" com pouquíssima roupa, a "novinha" afirmava que gostaria ainda de aplicar mais silicone para aumentá-la. Maitê prontamente aconselhou-a a não colocar mais "desse veneno" no corpo. Penélope a ignorou solenemente com uma careta e uma rebolada, e saiu cantarolando provocações. Logo depois, Maitê confessou:
- Essa daí se acha melhor que mulher por causa dessa bunda. Mas eu falo com elas: menina, para de bombar que cai tudo pro pé depois. Quando a gente é jovem acha que pode tudo. O corpo não reclama. Depois envelhece e vê que a coisa tem limite. Até careca a gente fica. O silicone, minha filha, cai tudo pro pé. Por isso que eu não tenho nada, sou mais a minha bundinha de pombo [mostra a bunda e dá uma gargalhada]. Mas eu tô bem pra minha idade e pras artes que eu faço, não tô? Isso aí é só porque é novinha e tá batendo porta. ${ }^{8}$ Lógico que essa bunda aí faz sucesso, né? O que tem de carro belíssimo parando pra ela, olha lá. Mas eu não dou conta desse movimento todo mais não. Cada uma com os seus talentos, né? O meu é bater um bolo, ${ }^{9}$ sou especialista. Me estico assim pra dentro do carro e mãos à obra! Isso ou uma gulosinha. ${ }^{10}$

Assim como Maitê, as "tias" - como são chamadas as travestis mais velhas - frequentemente falam do seu processo de envelhecimento associando-o a certa decadência física, como se a velhice fosse tirando aos poucos toda a feminilidade e beleza conquistada com muito esforço durante a juventude. Vemos que, como afirma Debert (1999), a velhice não é uma experiência universal e ahistórica. Seus sentidos, valores, imagens e vivências têm condições de possibilidade, são inscritas no tempo, no social e no cultural. Contudo, não se trata de negar as marcas da passagem do tempo inscritas no corpo, mas é fundamental compreendê-las como processos históricos de subjetivação.

No caso das travestis veteranas, as mudanças operadas pela passagem do tempo são percebidas, definidas e experimentadas, ao mesmo tempo, como limitações e motivos de orgulho. O envelhecimento implica uma nova administração de suas intervenções corporais, com a possibilidade de engordar, ficar careca ou ter o silicone deformado. Por isso, descrevem o avançar da idade como um momento em que a "natureza" mostra sua implacabilidade: se por tanto tempo elas construíram o feminino em um corpo inicialmente designado masculino, com o passar dos anos esse processo vai revelando determinados limites.

A hormonização foi bastante evocada na percepção da velhice, pela concepção de que, depois de certo tempo, os resultados inicialmente almejados (aumento dos seios, promoção de curvas, diminuição

5. Em outras pesquisas etnográficas sobre o mercado do sexo, essas dinâmicas de valorização da juventude e realocação de corpos tidos como velhos também se mostram presentes, como nos clássicos trabalhos O negócio do michê (2008), de Nestor Perlongher, e Garotas de programa: prostituição em Copacabana e identidade social (1985), de Maria Dulce Gaspar.

6. "Bombar" se refere às aplicações clandestinas de silicone industrial, realizadas para melhoramentos estéticos, principalmente, nos quadris, nádegas e seios, conforme a vontade de cada travesti. A profissional que realiza esse serviço é chamada de "bombadeira".

7. Os nomes utilizados são fictícios, refletindo a vontade de grande parte das interlocutoras. Apenas as que desejaram tiveram seus nomes preservados.

8. Expressão que significa fazer muitos programas, uma alusão ao entrar e sair do carro dos clientes.

9. Expressão que designa masturbação.

10. Expressão que designa sexo oral. 
de pelos etc.) não eram mais possíveis. E os efeitos colaterais, como ganho de peso, inchaço, dores e queimação nas pernas começavam a aumentar, implicando novas percepções de si, nem sempre compatíveis com a imagem de beleza e vivacidade construída na juventude (Oliveira, 2014).

Assim, coexistem e misturam-se duas representações recorrentes. Uma que afirma o peso do estigma da "travestilidade" somado ao da velhice, ressaltando um cenário negativo de solidão, melancolia, decadência física e desvalorização erótica; e outra que atenta para perspectivas mais positivas, frisando novas possibilidades, valores e habilidades associadas ao envelhecimento como travesti, corroborando aquilo que Simões (2004) também observou em seu estudo sobre homossexualidades masculinas e curso da vida.

Embora as narrativas sobre o envelhecimento fossem marcadas por queixas, o processo também era descrito pelo viés das facetas que o positivam: as "tias" ressaltam suas conquistas na produção do feminino nos corpos e nos gestos, além de se descrever como "vitoriosas" e "guerreiras", destacando que o simples fato de estar vivas dentro de um contexto tão precário e de trajetórias tão difíceis já demonstra uma grande vitória. Muitas afirmam que são "sobreviventes" ou estão "fazendo hora-extra", dada a percepção de que o envelhecimento como travesti é uma experiência pouco comum.

Fica claro que o envelhecimento acarreta impactos que marcam e limitam esses corpos e que são percebidos com tristeza pelas entrevistadas. Mas, a despeito de ser um período que pode trazer sofrimentos, em vários momentos e narrativas também percebeu-se o acionamento de outros contornos para esta etapa, vista como um período para vivenciar aquilo que antes não foi possível, como o sossego da casa própria, o acesso à educação, o parentesco eletivo, o engajamento na militância ou, ainda, a relação estabelecida com o corpo (que ainda sente prazer e que sente desejos).

Assim como foi observado no trabalho de $\mathrm{Si}$ queira (2004), para algumas travestis veteranas a velhice trouxe a imagem de "senhoras". A aparência senhoril muitas vezes motiva mais respeitabilidade e indica um reforço de uma certa feminilidade. Não mais uma feminilidade exotizada, sexualizada e juvenil, mas uma feminilidade madura e até certo ponto recatada, que permitiria, por exemplo, caminhar nas ruas durante o dia com maior tranquilidade. Apesar disso, entre as travestis, a possibilidade do envelhecimento e o alcance de certos marcos etários continuam sendo pautados por discursos que os descrevem como uma tarefa de "sorte" ou do "acaso".
A tensão relatada entre Maitê e Penélope também diz muito sobre as assimetrias e diferenças geracionais que marcam as demandas do mercado do sexo e as relações que ele atravessa. De um lado, as veteranas, como Maitê, procuram aconselhar as mais jovens sobre suas transformações corporais e disciplinar seus comportamentos ("porque as novinhas são umas abusadas"). De outro, as novatas, como Penélope, as chamam de "invejosas" e "recalcadas" e denunciam seu menor êxito no mercado sexual.

Muitas "tias" revelam alguns insucessos em suas transformações corporais (como o silicone que "cai para o pé") e possuem idade considerada avançada para o grande êxito na prostituição, enquanto as "novinhas", também chamadas de "patricinhas", são jovens, valor cultivado no grupo, pois as coloca em melhor posição no mercado do sexo. Além disso, elas tiveram acesso a toda uma tecnologia estética que não estava disponível até muito recentemente, o que as torna "mais bonitas" e melhor sucedidas em seu processo de "transformação". Por isso, muitas se consideram "mais mulher", "mais femininas" e "mais passáveis". 11

Ser "passável", termo que designa aquelas que conseguem "passar por mulher" nas mais diversas ocasiões, tem se constituído como algo de muito valor dentro do grupo. Tiago Duque (2013) discute a noção de "passabilidade", caracterizando-a como um regime de visibilidade/conhecimento que revela normas e convenções sociais que prescrevem performances de feminilidade e masculinidade, conferindo-lhes reconhecimento. Segundo esse autor, a constituição do "passar por" se dá "via a agência dos interlocutores diante de uma diversidade de elementos como a materialidade do corpo, a legitimidade dos documentos legais, a localidade espacial em que se encontram e a forma como se aprendeu a revestir o corpo, mas, sobretudo, porque há interação com os outros, os olhares dos outros" (p. 8).

São as mais jovens que, geralmente, alcançam o objetivo da "passabilidade", já que possuem relativo acesso a outras possibilidades técnicas de transformação corporal, como cirurgias plásticas, musculação, mega hair, depilação a laser, hidrogel e outros procedimentos estéticos não tão disponíveis, difundidos ou acessíveis anteriormente. Entre as "novinhas", o estilo de transformação corporal mais valorizado atualmente parece ser o denominado "ninfetinha", descrito por elas como "mais natural", com curvas mais enxutas e menos "exageradas", já que o exagero é apontado como marca registrada das mais velhas. Além disso, elas têm mais proximidade com os discursos de redução de danos provocados pelo silicone

11. Ver Ginsberg (1996) e Cooley e Harisson (2012), trabalhos estadunidenses que discutem as práticas e estratégias de passing - não só em termos de identidade de gênero, mas também de raça, sexualidade e nacionalidade - importantes para refletir sobre os riscos, limites e potenciais políticos de dicotomias identitárias, como o par transgênero e cisgênero. 
industrial. Este produto já não é tão utilizado pelas mais jovens, que conhecem de perto, a partir das experiências das veteranas, os problemas que ele pode causar a curto e longo prazos.

As tensões entre "tias" e "novinhas" também são explicitadas na fala da veterana Fabiana, que divide o trabalho de prostituta com o de cafetina. Dessa forma, vivencia relações íntimas com as mais jovens e frequentemente ressalta o desconhecimento das novatas diante de sua experiência de anos "na rua":

- Que preguiça, olha o tamanho do salto que elas vêm trabalhar. Tá tudo deslumbrada. Vê se eu ia cansar minhas pernas pra ficar de salto aqui pra esses homens. Eu fico é sentadinha. Elas que não sabem o que a gente já passou aqui. $\mathrm{O}$ tanto que a gente já correu da polícia. A gente corria demais deles aqui. Imagina correr da polícia em cima desse salto, aí? [Risos] Você não imagina o que era isso aqui. Hoje é uma paz. Há uns 10 anos atrás, mais ou menos, a polícia passava aqui todo santo dia. Primeiro vinha de carro, dando tiro pra cima pra assustar as bichas. Depois vinha pra dar batida em todo mundo. A gente tinha que sair correndo, eles levavam tudo quanto é veado pra passar a noite na delegacia. É, menina! Essas novinhas ficam aí se achando a última Coca-Cola do deserto por causa dos peitos, mas não passaram a metade do que a gente passou. Pra elas poderem desfilar de salto aqui a gente teve que tomar muita porrada.

Como aponta a fala de Fabiana, ao se relacionar com as travestis mais jovens, as "tias" frequentemente ressaltam a inexperiência das novatas e a ingratidão que elas demonstram em relação às dificuldades que passaram as veteranas para "abrir caminho para uma vida mais fácil". O cotidiano de trabalho atual das "pistas", considerado relativamente tranquilo em relação ao cenário das décadas passadas, é sempre posto em comparação com o que as veteranas viviam no local, antigamente; principalmente para marcar as experiências de agressão que sofreram até construir um ambiente mais propício para exercer a prostituição.

Para rebater comentários como os de Fabiana, as "novinhas" muitas vezes ressaltam que ainda sofrem com a violência policial, ainda que não na mesma frequência. Essas discussões não são apenas um indício de que talvez a atuação policial tenha mudado, no que concerne às travestis, mas, principalmente, fazem parte de uma estratégia de construção da autoridade das travestis mais velhas diante das novas, a partir de uma ideia de pioneirismo e sofrimento.
Dialogando com o trabalho de Simões (2004), Gustavo Saggese (2015) mostra que as primeiras gerações do movimento gay afirmaram-se como pioneiras a partir da narrativa do coming out, ou seja, da "saída do armário" como elemento central de uma política inédita de visibilização. No entanto, para nossas interlocutoras, a coragem de assumir certas práticas afetivas e sexuais é tomada como uma tensão menor se comparada aos riscos de construir determinadas corporalidades e viver o cotidiano das ruas.

As narrativas das veteranas visam colocá-las num lugar de poder e autoridade a partir do reconhecimento do seu sofrimento, do "abrir caminhos", dos saberes da rua e da produção de seus corpos específicos. E o questionamento desse lugar de autoridade, por parte das novatas, caminha muito pela insinuação de que as mais velhas não seriam mais belas e, por isso, seriam "recalcadas". Por sua vez, o ideal de beleza das "novinhas" passa por uma gradação entre mais feminina e menos feminina, que muitas vezes significa ser mais ou menos "passável" ou desejada pelos clientes. Essas experiências carregadas de tensões parecem estar relacionadas a uma certa rivalidade entre as veteranas - escoladas, já não tão atraentes - e as mais jovens - inexperientes, mas muito atrativas ao olhar dos frequentadores da "pista".

Vemos também como as novas possibilidades técnicas de construção do feminino têm trazido novas implicações identitárias e geracionais para as travestis e tornado os corpos mais plásticos à construção e desconstrução do que se deseja. Entre elas, essas novidades não se dão de forma desconectada de padrões de beleza mais amplos e práticas já legitimadas, e vemos surgir novos processos de composição das plurais noções de feminino que buscam. Assim, as distintas concepções estéticas, a maneira como a montagem é feita, os resultados que se quer com ela e os referenciais de beleza também não são mais exatamente os mesmos que marcaram as gerações anteriores.

Para Fabiana, a circulação de técnicas de transformação corporal e os referenciais de beleza estão temporal e geracionalmente marcados. Ela afirma como os ícones de beleza preferidos das travestis também variam conforme cada geração ${ }^{12}$ e seu ideal de feminilidade, ao declarar que "as novinhas só querem saber de Kim Kardashian. É muita plástica e nenhum talento. Sou de uma geração que reverencia Sophia Loren e Marilyn Monroe. Coisa clássica, não é só beleza. É talento e glamour." As práticas de "montagem" e de "transição" são contingentes, diferenciadas em ocasiões específicas, envolvendo graus variados de 
intervenção corporal, dependendo das inspirações, técnicas e objetivos (Vencato, 2015).

Segundo Marcos Benedetti (1997), é na convivência nos territórios de prostituição que as travestis incorporam os valores e formas do feminino, aprendem os truques e técnicas do cotidiano da prostituição e conformam gostos e preferências. A "pista" é um dos importantes espaços onde as travestis constroem-se corporal, subjetiva e socialmente. Contudo, é importante ressaltar que, diferentemente do que ocorria amiúde com as gerações mais antigas, parte das travestis adolescentes não tem sido expulsa de casa por seus pais, apresentando uma realidade diferente daquela narrada pelas mais velhas, em que as travestis, quando se "assumiam", tinham o espaço doméstico da família, quase sempre, insustentável.

Assim, com algumas experiências de espaços de sociabilidade mantidas em casa e na escola (ainda que marcadas por tensões e violências), o universo do mercado sexual parece tornar-se menos fundamental na formação das identidades e subjetividades das "novinhas", diferentemente do que apontam outras gerações de travestis. Além disso, soma-se o fato de que a internet tem se constituído como um espaço fundamental de troca de experiências e informações sobre os mais diversos assuntos do ser travesti: intervenções estéticas, prostituição, relacionamentos amorosos, contato com a família, direitos sociais etc.

A despeito desta inserção crescente das travestis mais jovens nos espaços familiares e formais, e da troca de informações online, mantém-se a importância da "pista" na experiência de muitas travestis, sobretudo como provedora de um simbolismo para a compreensão do ser travesti e na realização de suas transformações corporais (Duque, 2009).

Durante a convivência com nossas interlocutoras - que se iniciou na "pista" e chegou também aos espaços domésticos -, observamos uma coisa que parece fundamental nas experiências das travestis: o aprendizado com as outras sobre como se "montar", ou seja, transformar o corpo e se tornar travesti. Esse aprendizado envolve relações íntimas que acabam, muitas vezes, por ganhar o status de relações de parentesco eletivas: relações entre "mães" e "filhas". As narrativas sobre a entrada no universo das travestis mediante a prostituição e a realização das transformações corporais são geralmente marcadas pela relação com uma travesti mais velha e seus ensinamentos (e agenciamentos).

A partir desses relatos, é possível observar a ambiguidade presente nos regimes afetivos que envolvem gênero, trabalho, cuidado e intimidade, já que, embora as relações intergeracionais estejam, muitas vezes, carregadas de tensões e conflitos, elas também exprimem vínculos de afeto, aliança e solidariedade. As "tias", mais velhas e experientes, costumam fazer o papel de "madrinhas" ou "mães" ao orientar as mais jovens em suas "transformações". Ensinam a tomar os hormônios, aconselham sobre quando, onde e com quem injetar o silicone industrial (quando elas mesmas não o fazem). Também indicam cirurgiões plásticos, emprestam dinheiro para a realização dos procedimentos, comunicam as regras da rua e do trato com os clientes. Muitas vezes, elas constroem relações entre "mães" e "filhas", que vão além da relação entre cafetina e agenciada, ${ }^{13}$ e envolvem longos períodos de coabitação e convivência íntima.

A "maternidade" entre as travestis tem relação com o cuidar e com a gestação de uma nova pessoa. Não mais do adolescente afeminado que procura a cafetina, mas da travesti (Pelúcio, 2009). As mais jovens, as "filhas", muitas vezes dizem que nessas relações encontraram o amparo que lhes foi negado por suas famílias de origem. São comuns os relatos que apontam rompimentos com a "família de sangue" ou expulsões de casa associadas ao início da "transição", assim como a afirmação de uma necessidade consequente de constituição de uma malha de apoio social alternativa. Essa malha, por sua vez, costuma ser descrita como "uma família”, "uma outra família", "família do coração" ou "família da rua" (Henning, 2014).

\section{"Travesti quando envelhece"}

Como as narrativas anteriores indicam, as "tias" contam suas histórias e se constituem discursivamente como pessoas, frequentemente, em relação a certo sentido de pertencimento a uma geração. Os discursos que constroem tal pertencimento parecem menos ligados à idade cronológica e mais afeitos a memórias de um passado compartilhado. A evocação dessas lembranças revela o caráter de reconstrução da memória, que não pretende ser um retrato congelado e fidedigno da história e tampouco pressupõe que todas elas estiveram expostas da mesma maneira a certas fases do processo coletivo.

Assim considerada, a memória libertaria os fatos de uma temporalidade linear, externa, própria da reconstrução histórica, libertando as múltiplas temporalidades vivenciadas. O que é lembrado parece responder, de certa forma, às necessidades da ação atual (Kofes e Piscitelli, 1997). E o passado da "velha guarda" é comumente descrito por três elementos distintivos principais: a violência policial, a emergência do HIV e o glamour das décadas passadas.

13. Ver a dissertação de Sander (2015), que aborda as tensões, afetos e ambiguidades presentes nas relações que conjugam parentalidade eletiva e agenciamento, envolvendo travestis que são, ao mesmo tempo, "mães" e cafetinas. 
Por sucessivas décadas, a perseguição policial que enfrentavam esteve respaldada no Decreto-Lei $\mathrm{n}^{\circ} 3.688 / 41$, que, conforme suas disposições, previa a apreensão por crime de vadiagem, categoria penal que incluía as travestis profissionais do sexo simplesmente por estar nas ruas. Atravessando todo o período da ditadura militar e se estendendo até o final da década de 1980, esta contravenção penal implicou uma reformulação de suas vivências, ajustadas às imposições violentas desse aparato.

Como mecanismo de resistência, elas desenvolveram a prática de se cortar quando detidas nas delegacias de Vadiagem, forma encontrada para barganhar por libertação. Referindo-se a esse período como o "tempo do gilete na boca", elas escondiam giletes nas gengivas para se defender da repressão policial e das represálias de quem mais as ameaçasse. A fala de Verusca, atualmente com sessenta e um anos, explicita essa situação:

- Olha aqui meus braços: todos cortados! Isso era pra sair da cadeia... A gente não aguentava mais, ué! Sempre que eu entrava, eu era a primeira a ser cortada. Porque eu sabia que no outro dia eles iam bater na gente demais! Pra livrar daquele coro e choque (elétrico), eu me cortava.

Se, durante o período anterior à emergência do HIV, esta prática já era comum entre elas, a eclosão de seu quadro epidêmico no Brasil atualizou seu significado. Neste novo contexto, o ato de se cortar passa a ser visto pelos policiais como eminente ameaça de contaminação, sobretudo devido aos processos que estigmatizaram essa população no enquadramento de "grupo de risco". ${ }^{14}$ A memória de Verusca, inscrita no corpo por meio de muitas cicatrizes, revela uma estratégia de resistência e de sobrevivência muito comum naquele período. Nos relatos das veteranas, as torturas policiais são descritas de inúmeras formas: humilhação, constrangimento, violência sexual, espancamentos, torturas em pau de arara e choques elétricos, os quais eram dados, principalmente e não por acaso, em suas genitálias.

A emergência da Aids nos anos 1980 também delineou políticas e modos de ser, aparecendo no discurso das mais velhas especialmente ao falar do adoecimento e morte de várias amigas e companheiras de "pista", e dos remédios e tratamentos ainda em fase experimental. Esses relatos são atravessados por uma rede semântica que revela como a letalidade do vírus, naquele momento, gerou discursos médicos, midiáticos e populares que mostravam um tom segregacionista quando se tratava das travestis; assim como os homossexuais, elas eram fortemente culpabilizadas e tratadas como vetores de transmissão do HIV, como fica evidente no relato da veterana Sônia Luma:

\begin{abstract}
- Foi uma coisa horrorosa, sabe? Eu vi muitas meninas morrerem! Muitas amigas minhas morrerem! E tinha homens que vinham, batiam nas bichas. Diziam que as bichas tinham botado Aids neles. Nossa, foi um inferno! Teve uma época que a gente tinha que ficar tudo escondida porque a polícia batia também quando via a gente nos lugares... Diziam que a gente tava passando Aids pros outros. O pessoal passava, cuspia na gente... Colocava no muro da casa da gente assim "Poço de Aids! Sai fora aidética! Vai embora daqui Aids!”. Ai, um monte de coisa!
\end{abstract}

Ao ser evocadas, essas memórias mobilizam nas narradoras sentimentos de sofrimento e saudade das companheiras que faleceram. É uma dor que atravessa e constitui suas experiências, sendo impossível compreender seus processos de subjetivação na velhice sem passar por essas perdas. Como aponta Zamboni (2014), o período inicial da epidemia da Aids constituiu, para certa geração, uma ruptura brutal não só entre as pessoas que se infectaram, mas para todos que estavam próximos e compartilhavam de alguma forma esse sofrimento.

Por sua vez, o glamour retratado no passado das "tias" refere-se às viagens à Europa realizadas no período, bem como ao circuito artístico-cultural dos bailes e concursos de beleza de travestis, que ocorriam nas grandes cidades. O mais popular desses eventos foi o Baile dos Enxutos, que acontecia no Rio de Janeiro durante o carnaval, desde a década de 1950. Sua última edição ocorreu em 1982, no Cine São José, onde aconteceu a maioria desses bailes. Outros "bailes de travestis" também ficaram conhecidos, como o Berro do Paulistinha e o Grande Gala Gay (Green, 2000).

Esses eventos, que celebravam diversas representações visuais do feminino, são lembrados pelas veteranas com suspiros saudosos, como momentos de valorização do luxo e do brilho: performances de um feminino glamouroso e sofisticado, com penteados de festa e vestidos de gala. Em consonância com o trabalho de Guilherme Passamani (2015), as menções ao glamour evocam, além das referências aos bailes e ao carnaval, os momentos de realização de fantasias e sonhos, o "palco iluminado", que representava a possibilidade de exaltar corpos fora de certos padrões estéticos mais valorizados. Além disso, essas ocasiões faziam-se mais glamourosas para algumas, pois signi- 
ficavam a oportunidade de sair das periferias e desfilar pelas principais ruas dos centros urbanos.

Através das narrativas sobre o passado, as travestis vão se constituindo também no presente. Escoladas no processo de tornar-se travesti e afirmando-se sobreviventes de uma geração responsável por abrir as portas para as mais novas, as veteranas ocupam uma posição em suas redes de sociabilidade que relaciona-se com esses percursos. Porém, ao mesmo tempo que existem trocas (de reconhecimento, afeto, saberes e cuidado), essas relações também estão permeadas por tensões. Percebe-se, até mesmo, uma variação no uso dos termos utilizados para se referenciar às travestis mais velhas, que vão desde as categorias êmicas de "tias"/"mães" às pejorativas de "bicha velha"/"maricona", conforme os contextos relacionais. Utilizamos a seguinte fala de Sônia pra demonstrar essa situação:

- As travestis mais novas, elas não têm respeito com a outra que amassou barro pra hoje elas estarem na rua, né? Porque se hoje as travestis estão na rua, com paninho na cintura, é porque a velha amassou barro pra ela tá na rua, ali. Mas chegou aos trinta, meu bem, aí já é maricona: "Ai, bicha velha, bicha doida". Quando você vai dar conselho pra uma menina dessas de dezoito, vinte anos, pra ela juntar dinheiro, nossa senhora! "Ai, cê tá doida, cê tá velha, eu quero curtir!" [...] As pessoas não têm esse respeito de dizer assim: "Ah, você envelheceu, que bom!” Não tem isso. As mais novas debocham, elas riem... Já peguei várias meninas rindo, "Ah, é maricona! Tá velha!"

Percebe-se uma variedade nas denominações utilizadas pelas mais novas para se referir às mais velhas, que depende diretamente do tipo de sentimento investido nessas relações. O reconhecimento de suas trajetórias ou a desqualificação de suas experiências é o que irá, muitas vezes, orientar o uso dessas categorias de nomeação.

Algumas etnografias envolvendo relações de gênero, sexualidade e envelhecimento entre homens "maduros" homossexuais - e/ou que realizam práticas sexuais homoeróticas - também apontaram, de diferentes maneiras, esse volátil sistema classificatório, com as categorias "bicha velha", "tia velha", "maricona" etc. emergindo como status de desvalorização social, em contraposição às imagens do "coroa”, "paizão", "tiozão" etc., que passam a denotar, nesses contextos, alteridades mais positivas (Simões, 2004; Pocahy, 2011; Henning, 2014; Saggese, 2015; Passamani, 2016). Entre as travestis, a diferenciação da "bicha velha"/"maricona", de um lado, e da "tia"/"mãe", de outro, parece obedecer a essa mesma lógica valorativa: um conjunto de elementos mobilizados para (des)qualificar suas experiências e marcar conflitos ou afinidades.

Apesar de existir certo consenso em dizer que "as coisas melhoraram", ao menos em matéria de segurança, o cotidiano das "pistas" ainda é marcado por muitas tensões e violências. Por isso, a partir dos relatos de campo, percebe-se também que a relação das "tias" e "novinhas" está permeada por uma tentativa de negociar com o imediatismo que atravessa a vida das travestis. Dada a baixa longevidade ${ }^{15}$ e os poucos referenciais de envelhecimento que possuem, é comum que esse ideal de imediatismo transpareça nas formas como conduzem suas trajetórias.

As mortes de suas companheiras de trabalho e amigas também aparecem como um elemento dolorosamente naturalizado e corriqueiro em seus cotidianos e narrativas. Considerando a presença constante dos riscos e violências inscritos em seus corpos e subjetividades, "pensar no agora" acaba sendo uma estratégia lógica para construir suas vidas. Ainda segundo Sônia:

- A travesti não tem perspectiva de vida nenhuma, ela sabe que amanhã ela pode estar morta em qualquer lugar, então tudo que ela quer é pra hoje. E esse negócio de só querer pra hoje só prejudica, porque aí ela toma hormônio demais, né? Aplica silicone demais... [...] Elas têm certeza que elas não vão envelhecer... Tanto que a maioria fala "Ah, eu não vou chegar nem aos trinta, nem aos quarenta!”. Elas não têm aquelas perspectivas de envelhecer. Ela sabe que hoje ela tá viva, amanhã ela pode estar morta. E quando a gente envelhece é porque foi um acaso da vida.

"Sorte", "acaso da vida" e "hora extra" foram algumas das expressões utilizadas para narrar os processos de envelhecimento. Pensando nessas experiências, é necessário refletir também sobre as dinâmicas de periodização da vida que operam nestes cenários, uma vez que se percebe, em muitos casos, uma distorção dos referenciais etários tradicionalmente utilizados para pensar nos estágios não só de velhice, mas também de infância e juventude.

Sônia explicita essa ideia, ao afirmar que "a travesti começa a envelhecer quando ela sai de casa. No momento em que ela é expulsa de casa. Quando ela perde o vínculo com a família, ela começa a envelhecer". Neste sentido, para esta interlocutora, expulsa de casa aos doze anos (assim que começou a apresentar-se de forma mais feminina), o rompimento do vínculo com a família de origem e a necessidade de se sustentar com o trabalho sexual a empurraram em direção a certos sofrimentos e responsabilidades que

15. Segundo dados da Associação Nacional de Travestis e Transexuais (Antra), enquanto a população brasileira tem uma expectativa de vida que gira em torno dos setenta anos de idade, a população específica de travestis e transexuais vive, em média, apenas trinta e cinco anos. 
não condizem com as expectativas construídas para sua idade cronológica.

Explicitar a distância experienciada de modelos e histórias de vida mais próximos das expectativas e convenções vigentes em termos de gênero e sexualidade era uma estratégia frequente em seus relatos. Muitas vezes, a ideia de um não futuro ou uma não futuridade estava relacionada a um afastamento de marcos tidos como indispensáveis para alcançar a plenitude do percurso biográfico: casar-se, ter filhos "biológicos", possuir emprego estável e manter relações com a família de origem. Portanto, diante dessas relativas ausências de referências, "modelos-guia" ou horizontes de futuridade, nossas interlocutoras ressaltavam sua própria coragem: os enfrentamentos, improvisações e táticas pessoais empregadas para resolver os impasses que surgiam (Henning, 2014).

Pode-se dizer que essas experiências tensionam os esquemas normativos de institucionalização das etapas da vida, pensadas a partir de marcadores cisgêneros $^{16}$ - heterossexuais e reprodutivos. Além disso, vemos como esses esquemas levam à produção de imagens e representações negativas da velhice, na medida em que determinadas trajetórias não correspondem a certas expectativas sociais que figuram como as possibilidades viáveis, ou mesmo inteligíveis, de envelhecer. Assim, a vivência precoce de rupturas e dificuldades era apontada como uma construção forçosa da maturidade, indicada por um sentimento de adiantamento do processo de envelhecimento, um "salto nas etapas", que parece estar relacionada também à necessidade de certo embrutecimento e força para lidar com a dureza do cotidiano das ruas.

Podemos dizer que, de uma maneira geral, as narrativas sobre o envelhecimento em nossas pesquisas expressam a combinação de imagens tanto positivas quanto negativas desse processo. A ideia de degeneração física, de perda de feminilidade, de solidão e ausência de laços familiares combina-se com expressões de satisfação por ter alcançado essa fase da vida, que também é lida como um período de possível sossego, de retomar os estudos, de engajar-se no ativismo, de criar vínculos de parentesco eletivos e de constituir laços afetivos em suas redes de sociabilidade, essenciais para que elas se (re)criem nesses novos processos de percepção e construção de si.

\section{Considerações finais}

A partir de nossas experiências de pesquisa etnográfica, percebemos que conviver com travestis que se prostituem mostra que a concepção de "travesti" como uma identidade fixa ou um grupo homogêneo é perigosamente exotificante e simplificadora, na medida em que distorce as singularidades de cada trajetória e as especificidades de cada contexto. As mudanças corporais das travestis e a sua compreensão estão sempre envolvidas em uma tensa negociação e diálogo, que envolve travestis de perfis diversos, tecnologias, hierarquias e demandas dos clientes no mercado do sexo. Como sugere Butler (2004), a performatividade de gênero não pode ser teorizada separadamente da prática forçosa e reiterativa de outros regimes regulatórios e marcadores sociais da diferença, como idade e geração, que ficam bastante evidentes nos relatos recolhidos em campo.

A análise das dinâmicas distintivas e dos conflitos e vínculos que as envolvem nos alertou para a circulação de narrativas concorrentes e conflitantes de travestis de diferentes gerações, mostrando como a linguagem para falar das diferenças naquele contexto é especialmente articulada em termos de gênero, corpo e idade. Nessa análise das dinâmicas de diferenciação - que inscrevem distanciamentos e aproximações -, dos marcadores sociais da diferença e da circulação de categorias distintivas que atravessam as vivências das travestis, aproximamo-nos de uma noção de diferença como categoria analítica, conforme proposto por Avtar Brah (2006). Nessa perspectiva, a diferença se articula com experiências, relações sociais, subjetividades e identidades, pensadas como enunciados contingentes.

A ideia de diferença não é tomada em si mesma, de modo essencial, mas como categoria que remete a sujeitos sempre em processo. Assim, as diferenças observadas e relatadas em campo podem ser entendidas como trajetórias históricas e circunstâncias materiais e políticas que produzem as condições de possibilidade para o cotidiano das travestis. O esquema analítico de Brah não privilegia um nível macro ou micro de análise, mas, ao contrário, busca articular relações sociais, subjetividades e posições de sujeito, com o intuito de compreender a dinâmica de poder da diferenciação social sem ofuscar a dimensão da agência e da reflexividade.

Já que as vivências das travestis nas redes do trabalho sexual escancaram efeitos complexos e variados de uma população marcada por eixos de diferencia-

16. Advindo do latim, o vocábulo "trans" significa "através" ou "atravessar", ao passo que o prefixo "cis" significa "do mesmo lado". Assim, uma pessoa cisgênera seria aquela que se identifica com o gênero ao qual foi designada ao nascer, em função de certos marcadores anatômicos. Para uma discussão sobre os usos teóricos e políticos da noção de cisgeneridade, ver o artigo "Ensaio (travesti) sobre a escuta (cisgênera)", de Leila Dumaresq (2016). 
ção (econômicos, raciais, políticos, culturais, subjetivos, psíquicos e experienciais) que se cruzam em contextos históricos específicos, uma perspectiva que pensa na contingencialidade das experiências e na articulação dos eixos de diferenciação pode ser muito produtiva.

Analisar as formas de periodização da vida baseadas em narrativas êmicas sobre transformações espaço-temporais no universo das travestis revela como a estética corporal constitui um marcador geracional, uma vez que, ao longo dos anos, mudanças nos padrões estéticos e nas tecnologias de intervenção anunciam novas corporalidades e sensibilidades geracionais. Além disso, fica evidente como as relações intergeracionais são compostas por uma complexidade de laços que, ao mesmo tempo que estão marcados pelo afeto, aliança e cuidado, são também frágeis e permeados por tensões. Mas, apesar dos desacordos, rixas, enfrentamentos e mesmo situações de exploração, o suporte social e suas redes se estabelecem quase como um elemento característico do vínculo e da solidariedade intergeracional entre travestis trabalhadoras sexuais.

\section{Referências}

ANTUNES, Pedro Paulo Sammarco; MERCADANTE, Elisabeth Frohlich. Travestis, envelhecimento e velhice. Revista Kairós Gerontologia Temática, v. 14, n. 5, p. 109-132, 2011.

ANTUNES, Pedro Paulo Sammarco; MERCADANTE, Elisabeth Frohlich. Travestis envelhecem? 2010. Dissertação (Mestrado em Gerontologia) - Pontifícia Universidade Católica de São Paulo, São Paulo, 2010.

BENEDETTI, Marcos. Toda feita: gênero e identidade no corpo travesti. In: REUNIÓN DE ANTROPOLOGÍA DEL MERCOSUR, 2., 1997, Piriápolis, Uruguai. Anais... Uruguai, 1997.

BENEDETTI, Marcos. Toda feita: o corpo e o gênero das travestis. Rio de Janeiro: Garamond, 2005.

BRAH,Avtar. Diferença, diversidade, diferenciação. Cadernos Pagu, Campinas - SP, n. 26, p. 329-376, 2006.

BUTLER, Judith. Undoing gender. New York: Routledge, 2004.

BUTLER, Judith. Quadros de guerra: quando a vida é passível de luto? Rio de Janeiro: Civilização Brasileira, 2015.

BARROS, Myriam Moraes. Trajetória dos estudos velhice no Brasil. Sociologia, problemas e práticas, Lisboa, n. 52, p. 109132, set.-dez. 2006.

BRITTO DA MOTTA, Alda. As dimensões de gênero e classe social na análise do envelhecimento. Cadernos Pagu, Campinas - SP, n. 13, p. 191-221, 1999.

COSTA, Cicera Glaudiane. Travestilidades: incursões sobre envelhecimento a partir das trajetórias de vida de travestis da cidade do Recife. 2013. Dissertação (Mestrado em Antropologia) - Universidade Federal de Pernambuco, Recife, Pernambuco, 2013.

COOLEY, Dennis R.; HARISSON, Kelby. Passing/Out: sexual identity veiled and revealed. Surrey, UK: Ashgate Publishing, 2012

DEBERT, Guita Grin. A reinvenção da velhice: socialização e processos de reprivatização do envelhecimento. São Paulo: Edusp, 1999.

DEBERT, Guita Grin. O significado da velhice na sociedade brasileira. Acta Paul Enf, São Paulo, v. 12, p. 147-158, 2000. (Número especial, parte 1.)

DUMARESQ, Leila. Ensaio (travesti) sobre a escuta (cisgênera). Revista Periodicus, Salvador, n. 5, v. 1, 2016.

DUQUE, Tiago. Montagens e desmontagens: vergonha, estigma e desejo na construção das travestilidades na adolescência. São Carlos: Editora UFSCar, 2009.

DUQUE,Tiago. Gêneros incríveis: identificação, diferenciação e reconhecimento no ato de passar por. 2013. Tese (Doutorado em Ciências Sociais) - Universidade Estadual de Campinas, Campinas, São Paulo, 2013.

GASPAR, Maria Dulce. Garotas de programa: prostituição em Copacabana e identidade social. Rio de Janeiro: Zahar, 1985.

GINSBERG, Elaine K. Passing and the fictions of identity. Durham, UK: Duke UP, 1996.

GREEN, J. N. Além do carnaval. A homossexualidade masculina no Brasil do século XX. São Paulo: Editora Unesp, 2000.

HENNING, Carlos Eduardo. Paizões, tiozões, tias e cacuras: envelhecimento, meia idade, velhice e homoerotismo masculino na cidade de São Paulo. 2014. Tese (Doutorado em Antropologia Social) - Universidade Estadual de Campinas, Campinas, São Paulo, 2014.

HENNING, Carlos Eduardo. "Na minha época não tinha escapatória": teleologias, temporalidades e heteronormatividade. Cadernos Pagu, Campinas - SP, n. 46, p. 341-371, 2016.

KOFES, Suely; PISCITELLI, Adriana. Memória de "Histórias femininas - Memórias e Experiências". Cadernos Pagu, Campinas - SP, n. 8, p. 343-354, 1997.

LACOMBE, Andrea. Sobre saias, calças e bonés: expressão de gênero, geração e sedução entre mulheres que "gostam de mulher". Antropolitica, n. 34, p. 53-68, 2013.

NOGUEIRA, Francisco Jander. Mariconas: itinerários da velhice travesti, (des)montagens e (in)visibilidades. 2013. Tese (Doutorado em Sociologia) - Universidade Federal da Paraíba, João Pessoa, Paraíba, 2013.

OLIVEIRA, Lorena. Significado(s) do envelhecimento na experiência de travestis e transexuais. 2013. Monografia (Graduação em Ciências Sociais) - Universidade Federal de Minas Gerais. Belo Horizonte, Minas Gerais, 2013.

PASSAMANI, Guilherme. Batalha de confete no "Mar de Xarayés": condutas homossexuais, envelhecimento e regimes de visibilidade. 2015. Tese (Doutorado em Ciências Sociais) 
- Universidade Estadual de Campinas, Campinas, São Paulo, 2015.

PELÚCIO, Larissa. Abjeção e desejo: uma etnografia travesti sobre o modelo preventivo de aids. São Paulo: Annablume, 2009.

PEIXOTO, Clarice. Entre o estigma e a compaixão e os termos classificatórios: velho, velhote, idoso, terceira idade. In: BARROS, Myriam Moraes L. de (Org.). Velhice ou terceira idade? Estudos antropológicos sobre identidade, memória e política. Rio de Janeiro: Editora FGV, 2000.

PERLONGHER, Nestor. O negócio do michê. 2. ed. São Paulo: Editora Fundação Perseu Abramo, 2008.

SAGGESE, Gustavo Santa Roza. Entre perdas e ganhos: homossexualidade masculina, geração e transformação social na cidade de São Paulo. 2015. Tese (Doutorado em Antropologia Social) - Universidade de São Paulo, São Paulo, 2015.

SANDER, Vanessa. Entre manuais e truques: uma etnografia das redes do trabalho sexual entre travestis em Belo Horizonte. 2015. Dissertação (Mestrado em Antropologia Social) - Universidade Estadual de Campinas, Campinas, São Paulo, 2015.

SEFFNER, Fernando; DUARTE, Gustavo. E quando não há muito mais o que guardar no armário? Homossexualidades e processos de envelhecimento. Revista Bagoas, Natal - RN, n. 13, p. 57-82, 2015.

SCOTT, Joan. Experiência: tornando-se visível. In: SILVA, Alcione Leite. Falas de gênero: teorias, análises, leituras. Florianópolis: Editora Mulheres, 1999.

SIMÕES, Júlio Assis. Homossexualidade masculina e curso da vida: pensando idades e identidades sexuais. In: PISCITELLI, Adriana (Org.). Sexualidade e saberes: convenções e fronteiras. Rio de Janeiro: Garamond, 2004. SIQUEIRA, Mônica Soares. Sou senhora: um estudo antropológico sobre travestis na velhice. 2004. Dissertação (Mestrado em Antropologia) - Universidade Federal de Santa Catarina, Florianópolis, Santa Catarina, 2004.

VENCATO, Anna Paula. Entre "reais" e "virtuais": noções sobre risco e verdade em um clube brasileiro para crossdressers. Cadernos Pagu, Campinas - SP, n. 44, p. 367390, 2015.

ZAMBONI, Marcio. Herança, distinção e desejo: homossexualidades em camadas altas na cidade de São Paulo. 2014. Dissertação (Mestrado em Antropologia Social) - Universidade de São Paulo, São Paulo, 2014. 


\title{
"Tias" and "novinhas": aging and intergerational relationships among transgender sex workers in Belo Horizonte
}

\begin{abstract}
This article aims to articulate reflections on intergenerational relationships among travestis who are sex workers and their notions and perspectives of aging and periodization of life, using data derived from our ethnographic researchs, carried out in different areas of prostitution in Belo Horizonte. Conceiving categories referring generations and aging as discursive productions, we sought to understand which narratives are activated by the travestis to give shapes and singularities to their experiences. The focus is on intergenerational relations between tias and novinhas, as are called veterans and newcomers travestis: their conflicts, feelings, distinctive dynamics and shared memories. The constitution of these native categories points to a meshwork of relations, ties and tensions, which constitute social support networks crossed by the sex market.
\end{abstract}

Keywords: transgender, aging, generations, sex work, ethnography.

\section{"Tias" $y$ "novinhas": envejecimineto y relaciones intergeracionales entre travestis trabajadoras sexuales en Belo Horizonte}

\section{Resumen}

Este artículo se propone unir reflexiones sobre las relaciones intergeneracionales entre travestis trabajadoras sexuales y sus nociones y perspectivas del envejecimiento y la periodización de la vida, a partir de datos de nuestras investigaciones etnográficas, que se iniciaron desde distintas áreas de prostitución en Belo Horizonte. Concibiendo categorías relacionadas con el envejecimiento y las generaciones como producciones discursivas, hemos tratado de entender las narrativas conducidas por las travestis para dar contornos y singularidad a sus experiencias. La atención se centra en las relaciones intergeneracionales entre tias y novinhas, como se les llama a las veteranas y a las jóvenes: sus conflictos, sentimientos, dinámicas distintivas, recuerdos y experiencias compartidas. La constitución de estas categorías nativas apunta a una maraña de relaciones, vínculos y conflictos, que constituyen redes de apoyo social atravesadas por el mercado del sexo.

Palabras clave: travestis, envejecimiento, generaciones, trabajo sexual, etnografia.

Data de recebimento do artigo: 02/11/2016 Data de aprovação do artigo: 01/04/2017 
